\title{
Alkaline activation of ceramic waste materials
}

\author{
L. Reig ${ }^{1}$, M.M. Tashima ${ }^{2}$, L. Soriano ${ }^{2}$, M.V. Borrachero ${ }^{2}$, J. Monzó $^{2}$, J. Payá $^{2}$ \\ ${ }^{1}$ EMC, Universitat Jaume I, Av. Sos Baynat s/n 12071 Castelló de la Plana, Spain \\ ${ }^{2}$ Instituto de Ciencia y Tecnología del Hormigón (ICITECH), Universitat Politècnica de València, Camino de \\ Vera s/n 46022 Valencia, Spain.
}

Corresponding author: L. Reig; 1reig@uji.es

Tel.: +34964729163

Fax: +34964728106

E-mail addresses: lreig@uji.es; maumitta@hotmail.com; lousomar@gmail.com; vborrachero@cst.upv.es; jmmonzo@cst.upv.es; jjpaya@cst.upv.es

\begin{abstract}
Ceramic materials represent around $45 \%$ of construction and demolition waste, and originate not only from the building process, but also as rejected bricks and tiles from industry. Despite the fact that these wastes are mostly used as road sub-base or construction backfill materials, they can also be employed as supplementary cementitious materials, or even as raw material for alkali-activated binders. This research aimed to investigate the properties and microstructure of alkali-activated cement pastes and mortars produced from ceramic waste materials of various origins. Sodium hydroxide and sodium silicate were used to prepare the activating solution. The compressive strength of the developed mortars ranged between 22 and $41 \mathrm{MPa}$ after 7 days of curing at $65^{\circ} \mathrm{C}$, depending on the sodium concentration in the solution and the water/binder ratio. These results demonstrate the possibility of using alkali-activated ceramic materials in building applications.
\end{abstract}

Keywords: Ceramic waste, Waste management, Alkaline activation, Compressive strength. 


\section{Introduction}

The Portland cement clinker is the dominant binder used in concrete. However, its production requires approximately $850 \mathrm{kcal}$ and involves the emission of nearly $0.8-1.0 \mathrm{~kg}$ of $\mathrm{CO}_{2}$ per $\mathrm{kg}$ of cement produced [1]. The cement industry, together with the scientific community, is actively seeking alternatives to reduce the energy involved in cement production, to produce low- $\mathrm{CO}_{2}$ binders and to reuse waste materials from other industries.

Ceramic wastes in Spain abound and they are generated by not only the industry, but also by the construction sector. According to [2], approximately $950 \mathrm{~kg}$ per person/year derived from the construction field in 2007 in Spain, although this amount lowered in subsequent years due to the economic crisis $(520 \mathrm{~kg}$ per person and per year in 2009). Approximately $45 \%$ of construction and demolition wastes are ceramic in nature. Different ceramic materials production categories can be distinguished in accordance with the source of raw materials: structural ceramic products (i.e., bricks, roofing tiles, vaults, etc.), ceramic tiles and sanitary ware. As reported by HYSPALIT (the Spanish Association of Manufacturers of Bricks and Clay Roofing Tiles), the manufacture of structural ceramics increased progressively from 1994 to 2006 when almost 30 million tonnes were manufactured. The production rate dramatically decreased since then, and only 7.7 million tonnes were generated in 2010. Moreover, the Ceramic World Review survey [3] reported a world tile production of 9515 million square meters in 2010, of which $96.0 \%$ (9170 Mill $\mathrm{m}^{2}$ ) implied the 30 major manufacturing countries. Although the Spanish industry recorded a reduction in production of almost 40\% from 2006 to 2010 (608 to 366 million $\mathrm{m}^{2}$, respectively), it still ranked seventh in the list of manufacturers in 2010 with $3.8 \%$ of total world production. Since consumption in the Spanish market has diminished by $54.0 \%$ since 2006 , two thirds of manufactured tiles were exported.

Despite the vast majority of the ceramic wastes being used in landfills with a low added value, prior research has proved its suitability in concrete and as cementitious materials. In the studies by Medina et al. [4], up to 25.0\% of natural coarse aggregates were replaced with ceramic sanitaryware wastes to obtain concrete for structural purposes. Similarly, Pacheco-Torgal and Jalali [5] observed not only a slight increase in water absorption and permeability when replacing traditional coarse aggregates with ceramic wastes, but also superior durability when traditional sand was replaced. Furthermore, several studies have confirmed the potential of ceramic wastes to produce pozzolanic cements [6-9]. Among them, Puertas et al. [7] not only successfully used up to $35.0 \%$ of certain types of ceramic wastes as pozzolan admixtures, but also proved their suitability as raw materials for Portland cement clinker production. 
Although ceramic materials can be used as cement admixtures and concrete aggregates, in these applications only a portion of cement is replaced (usually $10-35 \%$ ) so, it is interesting to develop binders that are made entirely, or almost entirely, from waste materials [10]. This can be achieved by the alkali activation process. A conceptual model of the reaction processes involved was proposed by van Deventer et al. [11] for the metakaolin system. An aluminosilicate-based material is dissolved by a highly concentrated alkali hydroxide and silicate solution, giving rise to sodium or potassium silicate and aluminate monomers. These precipitate and form an alkali-aluminosilicate gel (amorphous) and sites for the nucleation of zeolitic type phases (nanocrystalline), brought about by the transformation of the gel. As Deventer et al. pointed out [11], the reaction mechanism is modified depending on the chemistry of the raw material.

The success of converting waste materials into useful products following this process has been extensively proved in materials such as silicoaluminous fly ash, metakaolin or blast furnace slag [12-14], and its suitability has also been confirmed for other waste materials, such as hydrated-carbonated cement [15], glass [16] or ceramic materials [17-19]. In the study by Puertas et al. [17], six different ceramic wastes were mixed with $\mathrm{NaOH}$ and sodium silicate solution to give a maximum compressive strength of $13 \mathrm{MPa}$ for pastes cured for 8 days at $40^{\circ} \mathrm{C}$. Mortars with similar compressive strengths (14 MPa) were obtained by Reig et al. $[18,19]$ by mixing red hollow bricks with a $\mathrm{NaOH}$ solution and by curing samples for 7 days at $65^{\circ} \mathrm{C}$. However, further research must be done in order to understand the influence of the alkali activator on the alkali activation process of ceramic materials of different natures. For this purpose, two different ceramic products, with very different sintering temperatures and chemical compositions, were selected: red clay bricks and porcelain stoneware. While the former are sintered at temperatures ranging from $800^{\circ} \mathrm{C}$ to $1000^{\circ} \mathrm{C}$ [9], porcelain tiles are usually sintered between $1190^{\circ} \mathrm{C}$ and $1220^{\circ} \mathrm{C}$ [20]. According to Baronio and Binda [21], powder from bricks is expected to present pozzolanic activity as the crystalline network is destroyed when the structural hydroxyl groups of clay minerals (phyllosilicates or sheet silicates) are lost $\left(600^{\circ} \mathrm{C}-900^{\circ} \mathrm{C}\right)$. According to the study by Zanelli et al. [22], which analyzed 93 porcelain stoneware samples, porcelain tiles are also presumed to react. Their mineralogy is composed of some crystalline phases, such as quartz, mullite or feldspars, which are dispersed throughout a main vitreous phase whose proportion varies from $40 \%$ to $80 \%$ depending on the sample.

This research aimed to develop binders by the alkali activation of two different ceramic waste materials (porous red clay brick and porcelain stoneware) and to analyze the influence of the alkali activator concentration on the mechanical strength and microstructure of the binders formed. 


\section{Experimental}

\subsection{Materials}

Two different ceramic waste materials were used for the alkaline activation process: red clay brick (B) and porcelain stoneware $(\mathrm{P})$. The materials were crushed in a jaw crusher to obtain a particle diameter of less than 4 $\mathrm{mm}$. This granulated material was then ground in a laboratory-type ball mill (alumina medium, 40 min). Particle size distribution was measured using a laser analyzer (Mastersizer 2000, Malvern Instruments). Figure 1 presents both cumulative curves. As shown, both powders presented a similar particle distribution, with particles ranging from 0.2 to $100 \mu \mathrm{m}, 90 \%$ in volume under $50 \mu \mathrm{m}$, and almost $7 \%$ had a diameter under $1 \mu \mathrm{m}$. Despite both ceramic materials having a mean particle diameter close to 20 microns, a slightly larger amount of thinner particles (under 10 micron) was observed in the red clay brick powder.

In Figure 2, both ground materials were examined by scanning electron microscopy (JEOL JSM-6300). The irregular shape of the milled particles is observed and particles show no significant porosity.

The chemical composition of the milled samples was determined by an X-ray fluorescence analysis (XRF). As shown in Table 1, the amount of $\mathrm{SiO}_{2}$ was larger in the porcelain waste ( $71 \%$ versus $\left.51 \%\right)$, while the presence of other compounds $\left(\mathrm{CaO}, \mathrm{K}_{2} \mathrm{O}, \mathrm{MgO}\right.$ and $\left.\mathrm{Fe}_{2} \mathrm{O}_{3}\right)$ was barely noticeable. In fact, $94 \%$ of porcelain stoneware was composed of $\mathrm{SiO}_{2}, \mathrm{Al}_{2} \mathrm{O}_{3}$ and $\mathrm{Na}_{2} \mathrm{O}$. For red clay brick waste, the sum of silica, alumina and sodium amounted to less than $70 \%$. In both cases, loss on ignition (LOI) was below $2 \%$.

The mineralogical composition of raw materials was determined by XRD in a Philips diffractometer PW1710 with $\mathrm{Cu} \mathrm{K} \alpha$ radiation under the routine conditions of $40 \mathrm{kV}$ and $20 \mathrm{~mA}$, from $5-55^{\circ}(2 \theta)$. As shown in Figure 3 , the major crystalline phase was quartz $\left(\mathrm{SiO}_{2}, \mathrm{PDF}\right.$ ard 331161), which was found in both waste materials. Other previously reported compounds in the mineralogy of ceramic materials [5,17], such as mullite $\left(\mathrm{Al}_{6} \mathrm{Si}_{2} \mathrm{O}_{13}\right.$, PDFcard 150776), anortite $\left(\mathrm{CaAl}_{2} \mathrm{Si}_{2} \mathrm{O}_{8}, \mathrm{PDF}\right.$ card 100489), wollastonite $\left(\mathrm{CaSiO}_{3}, \mathrm{PDF}\right.$ ard 350755$)$, gehlenite $\left(\mathrm{Ca}_{2} \mathrm{Al}_{2} \mathrm{SiO}_{7}, \mathrm{PDF}\right.$ card 350755$)$ or celite $\left(\mathrm{Ca}_{3} \mathrm{Al}_{2} \mathrm{O}_{6}, \mathrm{PDF}\right.$ card 320148$)$, were found in minor quantities. Mullite, an important constituent in porcelain material [23], was observed in the porcelain stoneware powder. 


\subsection{Preparation of paste and mortar samples}

To develop the alkali-activated binders, ceramic waste materials were mixed with an alkaline solution. The activating solution was prepared by dissolving sodium hydroxide pellets (Panreac, $98 \%$ purity) with water and a sodium silicate solution (Merck, Waterglass $\mathrm{SiO}_{2}=28 \%, \mathrm{Na}_{2} \mathrm{O}=8 \%, \mathrm{H}_{2} \mathrm{O}=64 \%$ ).

Paste samples were obtained by mixing ground ceramic with the required alkaline solution for 4 min, and they were cast in plastic containers. Mortar samples were prepared by mixing the ceramic material with the activating solution for $2 \mathrm{~min}$. Siliceous sand (4.36 modulus fineness and maximum particle diameter of $2 \mathrm{~mm}$ ) was then added and the mixing process was continued for a further 3.5-min period. The formed mortar samples were placed into a mould and were vibrated for $4 \mathrm{~min}$. Both pastes and mortars were stored in a thermostatically controlled bath at $65^{\circ} \mathrm{C}$ for 7 days at $100 \%$ relative humidity.

Table 2 summarises the mix proportions used in this study. Mixes are coded as ' $\mathrm{x} / \omega / \mathrm{m} / \mathrm{r}-\mathrm{c}$ ', where $\mathrm{x}$ is the type of ceramic waste (binder: $\mathrm{B}=$ brick and $\mathrm{P}=$ =porcelain), $\omega$ is the amount of water per $100 \mathrm{~g}$ of binder, $\mathrm{m}$ is the molality $\left(\mathrm{mol} / \mathrm{kg}\right.$ ) of $\mathrm{Na}^{+}$in the activating solution, $\mathrm{r}$ is the $\mathrm{SiO}_{2} / \mathrm{Na}_{2} \mathrm{O}$ molar ratio in the activating solution and $\mathrm{c}$ is the percentage of $\mathrm{Ca}(\mathrm{OH})_{2}(93 \%$ purity) used to replace ceramic waste.

A water/binder (w/b) ratio of 0.45 was used for the samples made with brick, which was lowered in samples ' $\mathrm{B} / 40 / 8.0 / 1.60$ ' and ' $\mathrm{B} / 35 / 9.0 / 1.60$ ' to analyze the influence of this parameter $(\mathrm{w} / \mathrm{b})$. Due to the reduced water absorption of the porcelain stoneware (less than $0.5 \%$ ) [24], the w/b ratio was lowered to 0.35 for all the porcelain waste mixes. A binder/sand (b/s) ratio of 1:3 was employed for all the mortars tested in this paper (see Table 2).

\subsection{Sample testing}

Compressive strength was determined on the alkali-activated mortars following the UNE EN 196-1 standard.

The microstructure was examined on paste samples using SEM-EDX (JEOL JSM-6300) and mineralogical phases were identified by X-ray diffraction XRD. Thermogravimetry (TG, TGA-850 Mettler-Toledo thermobalance) was done to determine the mass loss of samples in an $\mathrm{N}_{2}$ atmosphere using sealed pinholed aluminium crucibles at a heating rate of $10^{\circ} \mathrm{C} \mathrm{min}^{-1}$. Tests were run from $35^{\circ} \mathrm{C}$ to $600^{\circ} \mathrm{C}$ to assess the mass loss related to bonded water molecules or hydroxyl groups in the pastes. Samples were taken on day 7 of curing at $65^{\circ} \mathrm{C}$ and with a relative humidity of $95-100 \%$. 


\section{Results and Discussion}

3.1. Alkali activation of porcelain stoneware waste: preliminary study

Alkali-activated cement pastes and mortars using $\mathrm{NaOH}$ and sodium silicate solutions as activators were prepared by employing porcelain stoneware powder and after considering that the water demand for this residue was lesser than that for red clay brick. Thus, the water/binder ratio was fixed at 0.35 . Sodium molality and the $\mathrm{SiO}_{2} / \mathrm{Na}_{2} \mathrm{O}$ molar ratio varied and fell within the range of 6.5-8.5 and 1.12-2.13, respectively. Table 3 summarises the behaviour of the fresh pastes developed with the porcelain waste. As regards the setting of pastes, a strong dependence on the amount of $\mathrm{Ca}(\mathrm{OH})_{2}$ was observed so that only those mortars with $2 \%$ calcium hydroxide (replacing the porcelain stoneware powder) actually set during the first $24 \mathrm{~h}$. While mortars without calcium hydroxide did not harden, the setting time for those whose calcium hydroxide contents were higher than $5 \%$ was so short that it was not possible to place samples into the mould. The presence of soluble calcium in the binding material was required to produce a stable matrix after curing, which is in agreement with $[25,26]$, who observed that deficiencies in the $\mathrm{CaO}$ content of the raw material can be compensated by adding mineral additives.

3.2. Compressive strength development

\subsubsection{Effect of $\mathrm{Na}^{+}$concentration on the alkali activation of ceramic waste}

The compressive strength of the mortars mixed at a constant ' $\mathrm{SiO}_{2} / \mathrm{Na}_{2} \mathrm{O}$ ' ratio (1.60) and different $\mathrm{Na}^{+}$ concentrations $(6.0$ to $9.0 \mathrm{~mol} / \mathrm{kg})$ is depicted in Figure 4. For the activation of the porcelain stoneware-based mortars, and according to Section $3.1,2 \%$ of the waste material was replaced with $\mathrm{Ca}(\mathrm{OH})_{2}$. Furthermore, the presence of $\mathrm{Ca}(\mathrm{OH})_{2}$ was not necessary for the alkali-activated red clay brick based mixtures. The mortars containing B waste exhibited the highest compressive strength for a sodium concentration within the 6-7 mol/ $\mathrm{kg}$ range. However, the mechanical strength of porcelain mortars increased with alkali concentration. These results agree with the studies reported by Provis et al. [27], who observed that the optimum activator concentration depends on the precursor, and that this must be the case to balance the charges of tetrahedral Si and Al, thus avoiding the presence of unreacted sodium or silica. Duxson et al.[28] and Tashima et al. [29] also found an optimal concentration for the alkali activation of metakaolin and the fluid catalytic cracking catalyst residue, respectively. 


\subsubsection{Influence of $\mathrm{Na}^{+}$concentration and the water/binder $(w / b)$ ratio on alkali-activated red clay brick waste}

In order to assess the effect of the amount of water on the activating solution, clay brick-containing mortars were prepared with a w/b ratio that fell within the $0.45-0.35$ range. Although low workability was observed when reducing the quantity of water, it was sufficient to allow the mortars to be cast into the mould. As observed in Figure 5, compressive strength increased by more than $40 \%$ when the w/b ratio lowered from 0.45 to 0.35 , meaning that the amount of water was still sufficient to effectively wet brick particles. According to Komnitsas et al. [30], enhanced compressive strength may be motivated by the lesser available amount of free water after the hydration process, which is expected to diffuse or evaporate, leading to pores and cracks.

The good compressive strength behaviour observed when lowering the $\mathrm{w} / \mathrm{b}$ ratio also implies an improvement from the environmental point of view, since better mechanical properties are obtained while maintaining the ' $\mathrm{Na}^{+} /$binder' and ' $\mathrm{SiO}_{2} /$ binder' ratios constant ( $3.15 \mathrm{~mol}$ of $\mathrm{Na}^{+}$and $2.53 \mathrm{~mol}$ of $\mathrm{SiO}_{2}$ per kg of ceramic waste).

\subsection{Scanning electron microscopy studies}

The microstructure of the pastes obtained by the alkali activation of bricks and porcelain stoneware powders is represented in Figure 6. Both matrices look denser for larger amounts of sodium, and porcelain is more compact for a given sodium molality. However, brick pastes presented areas with a high sodium concentration (detected by EDS), which became more frequent in sample 'B/45/9/1.60' $(9 \mathrm{~mol} / \mathrm{kg})$. These results relate with the mechanical properties of brick mortars, suggesting that excess sodium is provided for concentrations higher than $7 \mathrm{~mol} / \mathrm{kg}$. Conversely, porcelain pastes looked denser with increasing sodium contents, which is consistent with the compressive strength presented by mortars. What this suggests is that even higher sodium concentrations may develop a denser microstructure, leading to higher compressive strength values. Furthermore, all the pastes presented unreacted particles surrounded by hydration products. According to the results obtained by Kourti et al. [16], porcelain particles are expected to influence the mechanical properties of the matrix more positively, as they are stronger and better bonded to the matrix than red clay brick particles. 


\subsection{X-Ray diffraction studies}

The diffraction patterns of the pastes obtained by the alkali activation of brick and porcelain wastes are presented in Figures $7 \mathrm{a}$ and $\mathrm{b}$, respectively. The XRD data of the ground material were plotted to make comparisons. As observed, the identifiable crystalline phases in the raw material were not completely dissolved by the alkaline solution, and most remained in the activated binder. Only wollastonite and gehlenite, found in small quantities in ground brick, were not identified in the activated pastes. Moreover, the amount of amorphous phases slightly increased in the porcelain binder when compared to the raw material, whose content increased with the highest sodium concentration $(9 \mathrm{~mol} / \mathrm{kg})$.

Small quantities of sodium carbonate (natrite, $\mathrm{Na}_{2} \mathrm{CO}_{3}$ ) were identified only in brick paste 'B/45/9/1.60'. This corroborates that a concentration of $9 \mathrm{~mol} / \mathrm{kg}$ provides brick samples with excess sodium which, according to Provis et al. [27], can lead to the formation of carbonate salts from atmospheric carbonation.

\subsection{Thermogravimetric analysis of pastes}

The differential thermogravimetric curves and the total mass loss of alkali-activated brick and porcelain pastes are represented in Figure 8. As observed, all the pastes had a similar total mass loss, which increased with a higher sodium concentration in the solution. According to Bernal et al. [31], this behaviour can be attributed to a more marked presence of $\mathrm{OH}^{-}$groups provided by $\mathrm{NaOH}$ in the activating solution.

All the pastes showed a single peak which centred at approximately $130^{\circ} \mathrm{C}$ and was attributed to the loss of the bound water of the pastes in $[29,32]$. Although several authors $[11,13,31,33]$ have identified zeolitic reaction products in alkali-activated binders, no zeolitic signals were recognised by thermogravimetry as, according to Bernal et al. [31], they tend to overlap with the peak that centres at $130^{\circ} \mathrm{C}$. Likewise, it was not possible to identify sodium carbonates with the TG analyses because their decomposition occurs at temperatures above $600^{\circ} \mathrm{C}[31]$. Additionally for the porcelain stoneware containing pastes, no $\mathrm{Ca}(\mathrm{OH})_{2}$ decomposition was detected at a high temperature $\left(500-600^{\circ} \mathrm{C}\right)$, which implies that this reagent was totally consumed during matrix formation. 


\section{Conclusions}

Alkali-activated binders have been obtained through the alkali activation of two different ceramic waste materials. During the alkali activation process of porcelain stoneware, the addition of $\mathrm{Ca}(\mathrm{OH})_{2}$ proved an essential constituent, and only those samples containing $2 \%$ of this reagent were obtained. The optimum mix for the alkali-activated porcelain stoneware was ' $\mathrm{P} / 35 / 9 / 1.60-2$ ' ( $9 \mathrm{~mol} / \mathrm{kg})$, which gives mortars whose compressive strengths come close to $30 \mathrm{MPa}$ after 7 curing days at $65^{\circ} \mathrm{C}$. Conversely for the red clay brick powder, the best compressive strength was obtained for mortar 'B/45/7/1.60' $(7 \mathrm{~mol} / \mathrm{kg})$, which diminished for higher sodium concentrations. The $\mathrm{w} / \mathrm{b}$ ratio was seen to markedly influence the compressive strength for brick mortars as it increased by $40 \%$ (29 to $41 \mathrm{MPa}$ ) when the w/b ratio lowered (from 0.45 to 0.35 ) and when the 'activator/binder' ratio remained constant. Further research must be conducted in order to completely understand the influence of calcium on the properties of the binders developed by the alkali activation of porcelain waste and to obtain mixtures with settings at room temperature.

\section{Acknowledgements}

The authors are grateful to the Spanish Ministry of Science and Innovation for supporting this study through Project GEOCEDEM BIA 2011-26947, and also to FEDER funding. They also thank Universitat Jaume I for supporting this research through Lucía Reig's granted research stay.

\section{References}

1. Puertas, F., García-Díaz, I., Barba, A., Gazulla, M.F., Palacios, M., Gómez, M.P., Martínez-Ramírez, S.:

Ceramic wastes as alternative raw materials for Portland cement clinker production. Cement Concrete Comp, 30 [9] pp 798-805 (2008)

2. Ministerio de Fomento de España, Catálogo de Residuos Utilizables en Construcción (2010). http://www.cedexmateriales.vsf.es/view/catalogo.aspx. Retrieved on 6 Dec (2012)

3. Stock, D.: World Production and Consumption of ceramic tiles. Tile Today, 73 pp 50-58 (2011)

4. Medina, C., Juan, A., Frías, M., Sánchez-de-Rojas, M.I., Morán, J.M., Guerra, M.I.: Characterization of Concrete made with Recycled Aggregate from Ceramic Sanitary Ware. Mater Construcc, 61 [304] pp 533-546

5. Pacheco-Torgal, F., Jalali, S.: Reusing ceramic wastes in concrete. Constr Build Mater. 24 [5] pp 832-838 
6. Lavat, A.E., Trezza, M.A., Poggi, M.: Characterization of ceramic roof tile wastes as pozzolanic admixture. Waste Manage, 29 [5] pp 1666-1674 (2009)

7. Puertas, F., García-Díaz, I., Barba, A., Gazulla, M.F., Palacios, M., Gómez, M.P., Martínez-Ramírez, S.:

Ceramic wastes as alternative raw materials for Portland cement clinker production. Cement Concrete Comp. 30 (9) 798-805 (2008).

8. Nuran, A., Mevlut, U.: The use of waste ceramic tile in cement production. Cement Concrete Res, 30, 497499 (2000)

9. Pereira-de-Oliveira, L.A., Castro-Gomes, J.P., Santos, P.M.S.: The potential pozzolanic activity of glass and red-clay ceramic waste as cement mortars components. Constr Build Mater. 31, 197-203 (2012)

10. Van Deventer, J.S.J., Provis J.L., Duxson P., Brice D.G.; Chemical Research and Climate Change as Drivers in the Commercial Adoption of Alkali Activated Materials. Waste Biomass Valor. 1, 145-155 (2010)

11. van Deventer, J.S.J., Provis J.L., Duxson P., Lukey G.C.: Reaction mechanisms in the geopolymeric conversion of inorganic waste to useful products. J Hazard Mater A139, 506-513 (2007)

12. Duxson, P., Fernández-Jiménez, A., Provis, J.L., Lukey, G.C., Palomo, A., van Deventer, J.S.J.: Geopolymer technology: the current state of the art. J Mater Sci, 42 [9] pp 2917-2993 (2007)

13. Bernal S.A., Rodríguez E.D., de Gutiérrez R.M., Provis J.L., Delvasto, S.: Activation of metakaolin/slag blends using alkaline solutions based on chemically modified silica fume and rice husk ash. Waste Biomass Valor. 3, 99-108 (2012)

14. Fernández-Jiménez, A., Palomo, A., Criado, M.: Microstructure development of alkali-activated fly ash cement: a descriptive model. Cement Concrete Res, 35, 1204-1209 (2005)

15. Payá, J., Borrachero, M.V., Monzó, J., Soriano, L., Tashima, M.M.: A new geopolymeric binder from hydrated-carbonated cement. Mater Lett, 74, 223-225 (2012)

16. Kourti, I., Amutha-Rani, D., Deegan, D., Boccaccini, A.R., Cheeseman, C.R.: Production of geopolymers using glass produced from DC plasma treatment of air pollution control (APC) residues. J Hazard Mater., 176, 704-709 (2010)

17. Puertas, F., Barba, A., Gazulla, M.F., Gómez, M.P., Palacios, M., Martínez-Ramírez, S.: Residuos cerámicos para su posible uso como materia prima en la fabricación de clínker de cemento Portland: caracterización y activación alcalina. Mater Construcc, 56, 281, 73-84 (2006)

18. Reig, L., Tashima, M.M., Borrachero, M.V., Monzó, J., Payá, J.: Nuevas matrices cementantes generadas por Activación Alcalina de residuos cerámicos. II Simposio Aprovechamiento de residuos agro-industriales como fuente sostenible de materiales de construcción, November 8-9, Valencia, Spain, 199-207 (2010a) 19. L. Reig, M.M. Tashima, M.V. Borrachero, J. Monzó, J. Payá: Residuos de ladrillos cerámicos en la 
producción de conglomerantes activados alcalinamente, I Pro-Africa Conference: Non-conventional Building Materials Based on Agroindustrial Wastes, October 18-19, Pirassununga - SP, Brazil, 18-21 (2010b)

20. García Ten F.J. Descomposición durante la cocción del carbonato cálcico contenido en el soporte crudo de los azulejos. Tesis de doctorado, Departamento de Ingeniería química, UJI (2005)

21. Baronio, G., Binda, L.: Study of the pozzolanicity of some bricks and clays. Constr Build Mater. 11 (1), 41 46.(1997)

22. Zanelli, C., Raimondo, M., Guarini, G., Dondi, M.: The vitreous phase of porcelain stoneware: Composition, evolution during sintering and physical properties. J Non-Cryst Solids. 357 3251-3260 (2011)

23. Carty, W.M., Senapati U.: Porcelain-Raw Materials, Processing, Phase Evolution, and Mechanical Behaviour. J. Am. Ceram. Soc. 81 [1], 3-20 (1998)

24. ASCER, COACV, COPUT, ITC-AICE, WEBER ET BROUTIN - CEMARKSA: Guía Baldosa Guía de la baldosa cerámica. IVE: Conselleria d'Obres Públiques, Urbanisme i Transports, $4^{\mathrm{a}}$ Ed. Valencia (2003)

25. Khater, H.M.: Effect of calcium on geopolimerization of aluminosilicate wastes. J Mater Civ Eng. 24, 92$101(2012)$

26. Bondar, D., Lynsdale C,J., Milestone, N.B., Hassani, N., Ramezanianpour, A.A.: Effect of adding mineral additives to alkali-activated natural pozzolan paste. Constr Build Mater. 25, 2906-2910 (2011)

27. Provis, J.L., Harrex, R.M., Bernal, A.S., Duxson, P., van Deventer, J.S.J.: Dilatometry of geopolymers as a means of selecting desirable fly ash sources. J non-cryst solids 358, 1930-1937 (2012).

28. Duxson, P., Provis, J.L., Lukey, G.C., Mallicoat, S.W., Kriven, W.M., van Deventer, J.S.J.: Understanding the relationship between geopolymer composition, microstructure and mechanical properties. Colloid surface A 269, 47-58 (2005),

29. Tashima, M.M., Akasaki, J.L., Castaldelli, V.N., Soriano, L., Monzó, J., Payá, J., Borrachero, M.V.: New geopolymeric binder based on fluid catalytic cracking catalyst residue (FCC). Mater Lett. 80, 50-52 (2012). 30. Komnitsas, K., Zaharaki, D., Perdikatsis, V.: Geopolymerisation of low calcium ferronickel slags. J Mater Sci 42, 3073-3082 (2007).

31. Bernal, S.A., Gutierrez, R.M., Provis, J.L., Rose, V.: Effect of silicate modulus and metakaolin incorporation on the carbonation of alkali silicate-activated slags. Cement Concrete Res. 40, 898-907 (2010).

32. Tashima, M.M. Produccion y caracterizacion de materiales cementantes a partir del silicoaluminato calcico vitreo (VCAS). Tesis de doctorado, Departamento de Ingeniería de la construcción y de proyectos de ingeniería civil, UPV (2012)

33. Provis, J.L., van Deventer, J.S.J.: Geopolymerisation kinetics. 2. Reaction kinetic modelling. Chem Eng Sci. $62,2318-2329(2007)$ 